\title{
EXIT SCHOOL AND ITS OUTCOMES ON HEALTH-RELATED FITNESS
}

\author{
Mohammed Zerf, Mohamed Hadjarkherfane \\ University Abdel Hamid Ibn Badis Mostaganem, Mostaganem, Algeria
}

Summary: School-based interventions are thought to be the most universally applicable and effective way to counteract low physical activity (PA) and fitness. Whereas Exit school it is not included. Method: For purpose, this controlled study verified the effect of Leaving school on the health relate to fitness among the unschooled. Results: Based on the validity of alpha health-related fitness test battery, the design of study and statistical processes applied within search limitation. Our results caution against school dropouts on levels of health relate to fitness among the unschooled. Admit in five motor abilities namely strength, speed, endurance, flexibility and coordinative abilities, according to present study. Reported in the benefit of student scholar as an active lifestyle. Conclusion: our results recommended all the Algerian dropouts -students to know the overall impact of participating and being involved in outdoor sport activities, subjected in this study as getting positive effects regarding active lifestyle, which in turn helps dropouts-students, to achieve a health-enhancing level of physical fitness and preventing them from disorders like obesity, laziness and stress related to life and their complication. A truth that leads us to recommended our teachers to understand the benefits of outdoor education sport or pro-socials activities contents as part of young people's educational experiences, to structure their free time in beneficial activities, including recreation, academic and cultural enrichment, opportunities for pursuit of individual interests and volunteer activities, especially before being expelled from their school.

Keywords: physical condition, Exit school, health and fitness.

DOI 10.2478/afepuc-2018-0003 
(C) Acta Facultatis Educationis Physicae Universitatis Comenianae

\section{Introduction}

School-based interventions are thought to be the most universally applicable and effective way to counteract low physical activity (PA) and fitness. Inspected by professionals worldwide via their valuations as key rooted throughout the program in both physical education and health education appropriate to meet the overall development of children and youth. Support in similar studies, as indicators serving to increase the physical condition of the general population (Jorgensen, Xu \& Constanza 2010). As well as children, adolescents and young (Lebedinskiy, Koipysheva, Rybina, Kudryavtsev, Ermakov, Osipov \& Sidorov 2017). Whereas these standards are absent when our students leave their school. Indicate by (Marnie 2004) that many more federal programs serve at-risk youth but do not have dropout prevention as a stated program goal. The case of this controlled study, which based their presumptuous on ALPHA Test to control the effect of leaving school on health fitness levels. Suggested in this study as a significant impact on their opportunities to participate in outdoorsport, the conditions that can affect health outcomes including physical levels (Symeon \& Lisette 2016). Support in several studies through their benefits related to mental health (Ken \& Andy 2016), as well as social capital (John \& Eric 2013).

From this perspective, our outcome in this study makes up by confirming the result of Algerian medical studies, which recommended the increase of the exercise in the Algerian community (Zerf 2016). Advanced by (Wenjiang 2012) in strengthen of sports activities to enhance the quality of follower life. Recommended by specialists in this topic built on the level of fitness to monitor changes in body composition via Algeria community, according to (Mohammed, Idris, Bagdad, Abelatif \& Ali 2016). Support by the European Union via the standards of ALPHA Test to assess the health-related fitness status in children and adolescents. Acquainted by similar (Dragan \& Ostojić 2013), as the ideal battery tests confirmed by (Jonatan, España-Romero, Castro-Piñero \& Manuel 2017) in evidence of fat impact associated with the health of children and adolescents related to upper body composition connected to decrease of musculoskeletal fitness correlate to cardiorespiratory and motor fitness. 


\section{Methods}

\section{Study population and design}

The research samples were elected by intentional manner included 32 students aged around 20 years, sex male. They were tested before and one year after they left school seats for the academic year 2015-2016 and 2016-2017, 3 months after the school entry. All participants were healthy with good habits without anything of mining medication on a regular basis. They were familiar with procedures and all participants provided their written consent. The study protocol was adopted by the Institute of PE. Piloted based on the ALPHAFitness Test Battery (Teenagers) (Ruiz, Castro-Piñero, España-Romero, Artero, Ortega, Cuenca, Jimenez-Pavón, Chillón, Girela-Rejón, Mora, Gutiérrez, Suni, Sjöström \& Castillo 2011). The exact ages of the participants were obtained by multiplying the number of months. Pubertal status (Tanner stages) the examinees provided a medical certificate establishing achievement. Weight was measured in the standing upright position with electronic scales with a precision of $100 \mathrm{~g}$. We determined standing height to the nearest $0.5 \mathrm{~cm}$ with the child's weight being equally distributed on the two feet, head back and buttock on the vertical land of the height gauge. We calculated BMI as the ratio of body weight to the square of height $\left(\mathrm{kg} \cdot \mathrm{m}^{2}\right)$ (Zerf, Atouti \& Farouk 2017). Flexed Arm Hang test the total time in seconds is recorded - the timing is stopped when the participant's chin falls below the level of the bar or head tilts backwards to enable sec the chin to stay level with the bar- to calculi the levels of this test, we use 1 point for $40 \mathrm{sec}$. Standing broad jump the measurement is taken from the take-off line to the nearest point of contact on the landing (back of the heels). Record the longest distance jumped, the best of three attempts. $20 \mathrm{~m}$ shuttles run to test the participant's score is the level and number of shuttles $(20 \mathrm{~m})$ reached before they were unable to keep up with the recording. Record the last level completed. For 4 x 10 m shuttle run, we record the time to complete the test in seconds to the nearest one decimal place.

\section{Statistical analysis}

Based on the data tests and the data analysis procedures used in study consisted of the computation of the means, standard deviations, the dependent t-test and correlation paired samples. We have chosen the descriptive statistics where we have calculated the conditions 
chosen for this experience. With a significance level was set at 0.05 . Statistical procedures were done using IBM SPSS 21.0.

\section{Results}

Depending on the alpha health-related fitness test battery for children and adolescents and statistical processes applied within search limitation. Our results improve the benefits school-based interventions located in PE activities sport before a leaving school in comparison with their results after their leaving school. Record in the present study according to standards alpha health-related fitness test practised coordinated to the norms set by the European Union. Confirmed in the case of this study by the significance of the dependent $t-$ test Table 1 and correlation list in Table2. In the benefit of school-based interventions as an effective way to counteract low physical activity (PA) and fitness, recorded in the present through less body fat associated with increased levels of physical performance record in the benefits of before leaving school. Advocate by BMI as an energy indicator relating total mass and height, which allow the comparison of athletic performance in various health $\&$ fitness tests (Suxing, Jing, Qi, Wen, Xiuyang et al. 2015). Where the most appropriate profiles report in this study support the benefits of school time structures as favourable conditions to realize optimal performance (Mohammed, Idris, Bagdad, Abelatif \& Ali 2016). Confirmed by the validity of ALPHA Battery test, definite in similar (Robinson, Diogo, Jorge Enrique, Mikel \& Felipe 2015) as reliable battery test administered by physical education teachers for assessing the levels of physical fitness in school environment. Suggested by European Union health authorities and schools as an ideal setting for monitoring youth fitness (Ruiz, Castro-Piñero, España-Romero, Artero, Ortega, Cuenca, Jimenez-Pavón, Chillón, Girela-Rejón, Mora, Gutiérrez, Suni, Sjöström \& Castillo 2011). Evidence guide us to indicate that school-based interventions are thought to be the most universally applicable and effective way to counteract low physical activity (PA) and fitness, report in this study as markers physical lifestyles (Kelishadi, Gheiratmand, Ardalan, Adeli, Mehdi; CASPIAN Study Group 2007). State in the present as a missing practice among our expelled from school. Owing to their teachers who do not rely on outdoor education sport or pro-socials activities as part of young people's educational experiences, especially before being expelled from school. Indicated in the previous as positive practices (Wu, Han, Zhang, Luo, Hu \& Sun 2017) for health and wellbeing of the individual in general (Mahdi, Masoud, Amin, Sadegh \& Ali 2014). 
Table 1

Characteristics and differences observed in the sample

\begin{tabular}{|c|c|c|c|c|c|c|}
\hline & & $\mathbf{N}$ & Mean & Std. Deviation & $\mathbf{T}$ & Sig. \\
\hline \multirow{2}{*}{$\begin{array}{c}\text { Body mass index } \\
\text { BMI }\end{array}$} & Before & 32 & 21.16 & 0.79 & \multirow[t]{2}{*}{-9.88} & \multirow[t]{2}{*}{0.00} \\
\hline & After & 32 & 24.49 & 3.36 & & \\
\hline \multirow{2}{*}{$\begin{array}{c}\text { Flexed Arm Hang } \\
\text { FAH }\end{array}$} & Before & 32 & 6.25 & 3.49 & \multirow[t]{2}{*}{14.64} & \multirow[t]{2}{*}{0.00} \\
\hline & After & 32 & 4.82 & 4.45 & & \\
\hline \multirow{2}{*}{$\begin{array}{c}\text { Standing broad jump } \\
\text { SBJ }\end{array}$} & Before & 32 & 2.49 & 1.18 & \multirow[t]{2}{*}{17.91} & \multirow[t]{2}{*}{0.00} \\
\hline & After & 32 & 1.84 & 1.17 & & \\
\hline \multirow{2}{*}{$\begin{array}{c}20 \mathrm{~m} \text { shuttle run } \\
\text { SR20 m }\end{array}$} & Before & 32 & 7.49 & .53074 & \multirow[t]{2}{*}{7.86} & \multirow[t]{2}{*}{0.00} \\
\hline & After & 32 & 5.57 & .45447 & & \\
\hline \multirow{2}{*}{$\begin{array}{l}4 \times 10 \mathrm{~m} \text { shuttle run } \\
\mathrm{SR} 4 \times 10 \mathrm{~m}\end{array}$} & Before & 32 & 9.13 & .45447 & \multirow[t]{2}{*}{-6.82} & \multirow[t]{2}{*}{0.00} \\
\hline & After & 32 & 10.86 & .45447 & & \\
\hline
\end{tabular}

Showed in similar (Ortega, Ruiz, Castillo \& Sjostrom 2008) through the impact of lower-body power which was inversely related to strength score (with a handgrip, standing broad jump, and an indicator of muscle endurance) in adolescents. The case of this study record via the relation BMI and alpha health-related fitness Test Battery; listed in Table 2. Evidence confirmed by (Jonatan, España-Romero, Castro-Piñero \& Manuel 2017) in effect of inactive lifestyle correlates with body fat gain associated with the health of children and adolescents. Reported in this actual study as strongly negative with alpha health-related fitness Test Battery in the benefit of less body fat record via Leave school in comparison with their lifestyle after their leaving school. As a missing practice to structure their free time in beneficial activities to increase their health-related fitness, according to Algerians studies subjections (Zerf, Mokkedes, Hamek, Houar \& Bengoua, 2016) indicate in the case of this study in benefits of school-based PE lessons.

Table 2

Pearson Correlation between BMI and ALPHA health-related fitness test battery

\begin{tabular}{|c|c|c|c|c|c|}
\hline Pearson Correlation & BMI & FAH & SBJ & SR20m & $\begin{array}{c}\text { SR4x10 } \\
\text { m }\end{array}$ \\
\hline Body mass index BMI & 1 & $-0.87^{* *}$ & $-0.95^{* *}$ & $-0.88^{* *}$ & $0.66^{* *}$ \\
\hline \multicolumn{6}{|c|}{${ }^{* *}$. Correlation is significant at the 0.01 level (2-tailed). } \\
\hline $\mathrm{N}$ & 32 & & & & \\
\hline
\end{tabular}




\section{Discussion}

Built on the power and validity of alpha health-related fitness test battery as feasible tests to assess health-related physical fitness in adolescents, according to (Tejero-Gonzalez, Martinez-Gomez, Bayon-Serna, Izquierdo-Gomez, Castro-Piñero \& Veiga 2013). Our results show that the benefits of School-based PE lessons curricular as healthy lifestyle activities sport among our scholar. Established in this study based on alpha health-related fitness test battery standards. Reported by similar (Manuel 2014) as valid battery test in school environments. Advanced (Moreno, Mesana, González-Gross, Gil, Ortega, Fleta, Wärnberg, León, Marcos \& Bueno 2007) in its possibility to estimate adiposity amounts on healthrelated fitness via Spanish adolescents. Sustained in the present through BMI correlation with ALPHA health-related fitness test battery. Confirmed via adolescents with fatness that has lower levels of fitness than their peers (Rocío, David, Carlos, Verónica, Jonathan \& Óscar 2013). Admit in the present study via upper body mass index (BMI) which affected muscle strength, endurance and cardiorespiratory functions among teenagers (Noha, Kader \& Mohamed 2016). Reported in the case of this study thought Flexed Arm Hang - Standing broad jump $-20 \mathrm{~m}$ shuttle run test $-4 \times 10 \mathrm{~m}$ shuttle run. In the benefit of PE curricular as healthy lifestyle activities sport among our scholar extra-curricular activities sports. Acknowledge advance by preventing studies (Lerner, Bornstein \& Leventhal 2015) in more time sports activities related to outcomes that are more physical and health. Agreement in its important for people to know the overall impact of participating and being involved in outdoor sports activities (Wilson 2009). Accounted in the present study as benefits healthy fitness practice permitting to students who left school to maintaining an overall athletic body composition. As the desire to maintain healthy weight correlates to upper physical performance. Advance by similar via the overweight as a serious health concern in the development of the child's musculoskeletal system relative to muscle strength and body composition (Miyatake, Miyachi, Tabata, Sakano, Hirao \& Numata 2012). Agreed in this study by the validity of alpha tests to control the impact of left school and its consequences on health-related fitness. Strategic indicate by specialists (Wenjiang 2012) in the benefits of sports activities to enhancing the quality of student or people life. Established in the present based on leaving school and its consequences on health-related fitness due to inactive lifestyle (Mahdi, Masoud, Amin, Sadegh \& Ali 2014). 


\section{Conclusions}

Our results raise the benefits of School-based interventions as the most universally applicable and effective way to counteract low physical activity (PA) and fitness. Support in the present by power and validity of alpha health-related fitness test battery. Sustained by European Union health authorities and schools as an ideal setting for monitoring youth fitness. Advance in similar, as markers of their lifestyles. The case of the present study, which required from our Dropouts students to adopt active lifestyle after their leaving school. To conclude, we recommended all the Algerian Dropouts -students to know the overall impact of participating and being involved in outdoor sports activities. Since their benefits raise on physical growth and development of teenagers, serving them to stating actives, fits and healthy, as well as it's preventing them from disorders like obesity, laziness and stress related to life and their complication. The case of our leavers recommended considering a sport and physical activity as a part of their leisure time. Evidence agreed in a higher level of physical activity and less time spent to increased health-related quality of life among leavers.

\section{References}

1. DRAGAN, C. \& T. S. OSTOJIĆ, 2013. Assessment of Physical Fitness in Children and Adolescents. Physical Education and Sport. 11(2): 135-145.

2. JOHN, H. \& M. A. ERIC M, 2013. International Guide to Student Achievement. London: Routledge.

3. JONATAN, R., V. J. ESPAÑA-ROMERO, CASTRO-PIÑERO \& J. C. MANUEL, 2017. ALPHA-fitness test battery: health-related field-based fitness tests assessment in children and adolescents. Nutr Hosp, 1210-1214. doi:10.3305/nh.2011.26.6.5270.

4. JØRGENSEN, S. E., X. LIU \& R. COSTANZA, 2010. Handbook of Ecological Indicators for Assessment of Ecosystem Health. USA: CRC Press.

5. KELISHADI, R., R. GHEIRATMAND, G. ARDALAN, K. ADELI, M. MEHDI GOUY \& CASPIAN Study Group, 2007. Association of anthropometric indices with cardiovascular disease risk factors among children and adolescents: CASPIAN Study. Int J Cardiol. 117(3): 340-348. doi:pmid:1686. 
6. KEN, G., \& S. ANDY, 2016. Routledge Handbook of Youth Sport. London: Routledge Handbook of Youth Sport.

7. LEBEDINSKIY, V. Y., E. A. KOIPYSHEVA, L. D. RYBINA, M. D. KUDRYAVTSEV, S. S. ERMAKOV, A. YU. OSIPOV \& L. K. SIDOROV, 2017. Age dynamic of physical condition changes in pre-school age girls, schoolgirls and students, living in conditions of Eastern Siberia. Physical Education of Students. 21(6), 280-286. doi: dx.doi.org/10.15561/20755279.2017.0604.

8. LERNER, R. M., M. H. BORNSTEIN \& T. LEVENTHAL, 2015. Handbook of child psychology and developmental science. Hoboken, New Jersey: Wiley.com.

9. MAHDI, T., A. MASOUD, A. AMIN, A. SADEGH \& A. ALI, 2014. A relationship between physical activity and healthy quality of life in students. Turkish Journal of Sport and Exercise. 16(2): 15-21. doi:DOI: 10.15314/TJSE.201428100.

10. MANUEL, J. C. G., 2014. The ALPHA Health - Related Fitness Test Battery for Children and Adolescents "Test Manual". eu : School of Medicine, University of Granada. Retrieved from www.thealphaproject.eu.

11. MARNIE, S. S., 2004. School dropouts: education could play a stronger role in identifying and disseminating promising. USA: Diane Pub Co.

12. MIYATAKE, N., M. MIYACHI, I. TABATA, N. SAKANO, T. HIRAO \& T. NUMATA, 2012. Relationship between muscle strength and anthropometric, body composition parameters in Japanese adolescents. Health. 4(1): 1-5. doi:10.4236/health.2012.41001.

13. MOHAMMED, Z., MM. IDRIS, H. BAGDAD, H. ABELATIF \& B. ALI, 2016. Impact of Body Composition on Optimal Competitive Body and its Consequences on Athletic Performance in Healthy Young. Int $J$ Womens Health Wellness. 2(4). IJWHW-2-041. doi:10.23937/2474-1353/1510041.

14. MORENO, L.A., M. I. MESANA, M. GONZÁLEZ-GROSS, C. M. GIL, F. B. ORTEGA, J. FLETA, J. WÄRNBERG, J. LEÓN, A. MARCOS \& M. BUENO, 2007. Body fat distribution reference standards in Spanish adolescents: the AVENA Study. Int J Obes (Lond). 31(12): 1798-805. doi:10.1038/sj.ijo.0803670.

15. NIKKI, W., 2009. Impact of Extracurricular Activities on Students. University of Wisconsin-Stout, 8 .

16. NOHA, A., K. KADER ABDEL \& K. A. MOHAMED, 2016. Relation between body mass index percentile and muscle strength and endurance. Egyptian Journal of Medical Human Genetics. 17(4): 367-372. doi:doi.org/10.1016/j.ejmhg.2016.01.002. 
17. ORTEGA, FB, RUIZ JR, CASTILlO MJ, SJOSTROM M. (2008). Physical fitness in childhood and adolescence: a powerful marker of health. Int J Obes (Lond). 32(1): 1-11.

18. ROBINSON, R., R. DIOGO, E. JORGE, I. MIKEL \& L. FELIPE, 2015. Reliability of Health-Related Physical Fitness Tests among Colombian Children and Adolescents: The FUPRECOL Study. PLoS ONE, 10(10), e0140875. doi: doi.org/10.1371/ journal. pone. 0140875 .

19. ROCÍO, I., M. DAVID, M. T. CARLOS, C. VERÓNICA, R. JONATHAN \& L. V. ÓSCAR, 2013. Are poor physical fitness and obesity two features of the adolescent with Down syndrome? Nutr Hosp. 28(4): 1348-1351. doi:10.3305/nh.2013.28.4.6566.

20. RUIZ J. R., J. CASTRO-PIÑERO, V. ESPAÑA-ROMERO, E. G. ARTERO, F. B. ORTEGA, M. M. CUENCA, D. JIMENEZ-PAVÓN, P. CHILLÓN, M. J. GIRELAREJÓN, J. MORA, A. GUTIÉRREZ, J. SUNI, M. SJÖSTRÖM \& M. J. CASTILLO, 2011. Field-based fitness assessment in young people: the ALPHA health-related fitnes. Br J Sports Med. 45(6): 518-24. doi:10.1136/bjsm.2010.075341.

21. SUXING, S., L. JING, G. QI, Z. WEN, W. XIUYANG et al., 2015. Body Mass Index Is Associated with Physical Performance in Suburb-Dwelling Older Chinese: A CrossSectional Study. PLOS One. 10(3), e0119914. doi:doi.org/10.1371/journal.pone.0119914.

22. SYMEON D. \& B. LISETTE, 2016. Families, Young People, Physical Activity and Health. London: Routledge.

23. TEJERO-GONZALEZ, CM., D. MARTINEZ-GOMEZ, J. BAYON-SERNA, R. IZQUIERDO-GOMEZ, J. CASTRO-PIÑERO \& O. L. VEIGA, 2013. Reliability of the ALPHA Health-Related Fitness Test Battery in Adolescents With Down Syndrome. $J$ Strength Cond Res. 27(11): 3221-4. doi:10.1519/JSC.0b013e31828bed4e.

24. WENJIANG D., 2012. Informatics and Management Science III. London: Springer.

25. WU, X. Y., L. H. HAN, J. H. ZHANG, S. LUO, J. W. HU \& K. SUN, 2017. The influence of physical activity, sedentary behavior on health-related quality of life among the general population of children and adolescents: A systematic review. PLoS ONE. 12(11), e0187668. doi:https://doi.org/10.1371/journal.pone.0187668.

26. ZERF, M., 2016. Impact of theoretical courses on physical health performance. BLDE Univ J Health Sci. 1(1): 44-8. Retrieved from http://www.bldeujournalhs.in/text.asp? 2016/1/1/44/183285.

27. ZERF, M., N. ATOUTI \& A. BEN FAROUK, 2017. Abdominal obesity and their association with total body: fat distribution and composition. Case of Algerian teenager 
male high school students. Physical education of students. 21(3), 146-151. doi: 10.15561/20755279.2017.0308.

28. ZERF, M., M. I. MOKKEDES, B. HAMEK, A. HOUAR \& A. BENGOUA, 2016. Impact of Body Composition on Optimal Competitive Body and its Consequences on Athletic Performance in Healthy Young. International Journal of Women's Health and Wellness. 2(6). doi:10.23937/2474-1353/1510041. 